\title{
La canción de Aslan que crea el mundo
}

\author{
Braulio Fernández \\ UNIVERSIDAD DE LOS ANDES (CHILE) \\ bfernandez@uandes.cl
}

Resumen: En El sobrino del mago, la primera de sus crónicas, C.S. Lewis narra la creación de Narnia por Aslan -figura de Cristo- a través de la música. Esta alegoría funciona no solo porque la música, forma pura, es belleza captada por el sentido fundamental, sino ante todo porque es una cabal analogía de la perfección trinitaria del Dios cristiano.

Palabras clave: C.S. Lewis, Narnia, alegoría, creación del mundo, música, Santísima Trinidad.

Abstract: In the The Magician's Nephew, first of his chronicles, C.S. Lewis tells the creation of Narnia by Aslan -figure of Christ- through music. This allegory is true not only because music, as pure form, is beauty captured by the fundamental sense, but foremost because it is an accurate analogy of the perfection of the Trinitarian Christian God.

Keywords: C.S. Lewis, Narnia, Allegory, Creation of the World, Music, Holy Trinity.

En El sobrino del mago, hacia el final del capítulo 8, "La pelea junto al farol", y en el capítulo 9, titulado "La fundación de Narnia", se narra cómo Aslan creó ese mundo a través de la música:

El león iba y venía por aquel territorio vacío y entonaba una nueva canción. Era más dulce y melodiosa que la que había cantado para invocar a las estrellas y al sol; una suave música susurrante. Y mientras andaba y cantaba, el valle se llenó de hierba verde que se desparramaba a partir del león como un estanque. La hierba ascendió por las faldas de las pequeñas colinas como una oleada, y en pocos minutos trepaba ya por las laderas inferiores de las lejanas montañas, convirtiendo aquel mundo joven en algo cada vez más mullido ${ }^{1}$.

1 C.S. LEWIS, El sobrino del mago (Destino, Barcelona, 2005) 143. Esta traducción que sigo, de Gemma Gallart, se publica con las ilustraciones originales de Pauline Baynes. 
Luego de la creación de los árboles vendrá la fabulosa aparición de los animales desde la tierra (“¿Eres capaz de imaginar un prado cubierto de hierba que borbotea como el agua en una olla?”2) y la fundación propiamente dicha, que comentaré al final de este artículo.

Al principio, la música es monofónica y se siente desde la distancia. Corresponde a la creación de la luz y las estrellas, de la propia esfericidad del mundo (Narnia). Luego se hace más compleja con tonos graves y agudos, polifónica, y corresponde a la creación de la vida natural y vegetal. Este es el momento de la cita anterior.

En una tercera fase, la música adquiere una naturaleza particular, al menos para quienes la oyen: comienza a existir una conexión entre ella "y las cosas que sucedían"3. Si bien todo salía "de la cabeza del león" ${ }^{4}$-es decir, las acciones de Aslan son producto de su inteligencia, ciertamente puesta en acto-, "cuando uno escuchaba su canción oía las cosas que creaba; cuando miraba a su alrededor, las veía" 5 . Como se comprende, por una parte hay en el león un querer que es al mismo tiempo acto creativo (dictum et factum, diríamos); para Aslan, como para el Dios cristiano de quien es alegoría, pensar, querer y crear constituyen un mismo acto. Pero, y por otra parte, para los testigos de esta creación es perfectamente perceptible dicha unidad creativa (que sin duda lo fue también para Adán, aunque de otra forma: el jardín de Edén ya existía íntegro ante sus ojos cuando el Señor Dios le mandó poner nombre a las cosas que allí eran (Gn 2, 18-20)). "Todo adquiere vida y crece"6; "todo rebosa vida y desarrollo" 7 , dirán esos testigos, incluso cuando de la barra del farol que la bruja fallidamente lanzó al león comience a nacer un verdadero farol, el famoso farol de Narnia.

Pero la canción vuelve a cambiar; se torna mucho más parecida a una melodía, aunque también consigue mayor desenfreno. "Hacía que se quisiera correr, saltar y trepar; [...] que entraran ganas de gritar; [...] que se deseara correr hacia otras personas y abrazarlas o pelear con ellas" ${ }^{\prime}$, etc.

\footnotetext{
C.S. LEWIS, El sobrino ..., 154.

C.S. LEWIS, El sobrino ..., 146.

C.S. LEWIS, El sobrino ..., 147.

C.S. LEWIS, El sobrino ..., 147.

C.S. LEWIS, El sobrino ..., 153.

C.S. LEWIS, El sobrino ..., 152.

$8 \quad$ C.S. LEWIS, El sobrino ..., 155.
} 
Evidentemente que todo esto remite, al fin, a la idea de una armonía que se impone sobre el caos; a una fuerza creadora que actúa con y a través de la armonía; y cuyos resultados son también eso: armonía. Un pulchrum que se cierne sobre el desorden, que lo conquista instaurando la proporcionalidad, pero que es también vitalidad. Mejor dicho: la armonía, como orden y proporcionalidad, es vital. Vitalizante y vitalizadora. Tanto, que esa armonía se romperá cuando el mal, encarnado en la Bruja Blanca, se apodere completamente de Narnia: todo será siempre invierno; frío, hielo y nieve en cada rincón del mundo.

Sugerentemente, en El Silmarillion -la obra más preciada, pero que no pudo terminar, de su gran amigo J.R.R. Tolkien-, Eru ("el Único, que en Arda es llamado Ilúvatar") ${ }^{9-10}$ también crea el mundo a través de la música. Es una melodía inefable que propone a los Ainur, quienes la ejecutan maravillosamente y a la perfección; hasta que uno de ellos, Melkor, desafina y cae (aunque conviene precisar la naturaleza de esta desafinación. Dice el texto: "Pero a medida que el tema [propuesto por Ilúvatar a los Ainur] prosperaba, nació un deseo en el corazón de Melkor: entretejer asuntos de su propia imaginación que no se acordaban con el tema de Ilúvatar, porque intentaba así acrecentar el poder y la gloria de la parte que le había sido asignada"11.

La imagen del recurso a la música para la fundación de Narnia funciona como una metáfora del orden armónico que el creador, Aslan en este caso, impone al caos. La idea ya está en textos antiguos, como por

9 J.R.R. TOLKIEN, El Silmarillion (Minotauro, Barcelona, 1986) 6.

10 "En el principio estaba Eru, el Único, que en Arda es llamado Ilúvatar; y primero hizo a los Ainur, los Sagrados, que eran vástagos de su pensamiento, y estuvieron con él antes que se hiciera alguna otra cosa. Y les habló y les propuso temas de música; y cantaron ante él y él se sintió complacido. Pero por mucho tiempo cada uno de ellos cantó solo, o junto con unos pocos, mientras el resto escuchaba; porque cada uno solo entendía aquella parte de la mente de Ilúvatar de la que provenía él mismo, y eran muy lentos en comprender el canto de sus hermanos. Pero cada vez que escuchaban, alcanzaban una comprensión más profunda, y crecían en unisonancia y armonía. Y sucedió que Ilúvatar convocó a todos los Ainur, y les comunicó un tema poderoso, descubriendo para ellos cosas todavía más grandes y más maravillosas que las reveladas hasta entonces; y la gloria del principio y el esplendor del final asombraron a los Ainur, de modo que se inclinaron ante Ilúvatar y guardaron silencio". J.R.R. TOLKIEN, El Silmarillion, 6.

11 J.R.R. TOLKIEN, El Silmarillion, 6. 
ejemplo en el Timeo de Platón. Allí, a poco de iniciado el diálogo, el mismo Timeo dice que:

[...] como el dios quería que todas las cosas fueran buenas y no hubiera en lo posible nada malo, tomó todo cuanto es visible, que se movía sin reposo de manera caótica y desordenada, y lo condujo del desorden al orden, pues pensó que este es en todo sentido mejor que aquel $(30 a)^{12}$.

Sabemos que hay en esto un influjo pitagórico, a propósito de la estructura geométrico-musical del mundo. Pitágoras pensaba que la esencia última de la realidad era numérica. Y así, por ejemplo, la distancia entre los planetas era proporcional a la distancia de las notas en la escala musical. De ahí también su idea de la "música de las esferas celestes", que es a la vez -me parece- una manifestación metafórica de un concepto más bien metafísico de orden y armonía: la unidad, simpleza y belleza del Ser. Como sea, en el Timeo, el demiurgo "actúa como un músico creando una escala tonal" 13 .

Pero la fundación de Narnia no es solo armonía que se impone al caos. Hay una diferencia mucho más radical y absoluta, que proviene de la cosmología cristiana: la creación que se hace ex nibilo, a partir de la nada. A diferencia de las doctrinas pitagóricas y las de Platón, el creador de Narnia no solo impone un orden proporcional y armónico al caos preexistente -que, en realidad, podría considerarse una condición sine qua non de toda creación-, sino que crea a partir de la nada. Y aunque el Dios judeocristiano lo haga a través de su Palabra y su Espíritu, y no de la música, el eco con el comienzo del libro del Génesis es rotundo: "En el principio creó Dios el cielo y la tierra. La tierra era caos y vacío, la tiniebla cubría la faz del abismo y el espíritu de Dios se cernía sobre la superficie de las aguas. Dijo Dios: 'Haya luz'. Y hubo luz' (Gn 1, 1-3).

Pero volviendo a la música, la imagen de Aslan creando Narnia, y especialmente el vínculo que establece en lo sucesivo con ella -sobre lo cual también volveré al final-, tiene también una relación evidente con el mito, el de Orfeo en este caso. Como nos lo han transmitido Virgilio y Ovidio, Orfeo, hijo de Apolo, recibió la lira de su padre y con ella no solo llegó a ser un gran poeta, sino que pudo encantar a las bestias con

12 Sigo la edición de M.A. DURÁn y F. LISI. Platón, Diálogos VI. Filebo, Timeo, Critias (Gredos, Madrid, 1992) 125-262.

13 Nota 29 de los editores a 36b, 179-180. 
su música, y hacer que los árboles y las rocas se movieran. Tanto era su poder, que entre otras hazañas libró a los argonautas del terrible canto de las sirenas y les permitió sortear obstáculos tremendos en su viaje, como Escila y Caribdis... Pero quizás la proeza más notable de todas las que logró con su música tuvo lugar cuando su amada Eurídice bajó al inframundo, tras haber sido herida de muerte por pisar una sierpe venenosa cuando escapaba del pastor Aristeo, que pretendía violarla. Orfeo pudo ingresar a la mansión de Hades, convencer a Caronte de que lo llevara al otro lado y, más insólito aún, conmover con su canto al dios y a su esposa, Perséfone, hasta las lágrimas. Tanto, que a Eurídice se le permitió volver a la superficie.

(La desgracia que vino después no tuvo que ver con la música, sino con el amor, tema que excede a este artículo...).

Pienso que el estrecho vínculo de la música y el orfismo no nos debe extrañar: de todas las artes, la música es la más misteriosa. El teatro es casi más mágico, sí, pero no tiene esa impronta inefable. De ambos no queda nada tras su ejecución; pero el teatro es un juego y la música algo muy serio. Por lo demás, el teatro es realidad concentrada; la música, en cambio, realidad en expansión... De hecho, la pregunta acerca de qué sea exactamente la música, es, con toda probabilidad, una de las más difíciles de responder.

Desde luego, es pura forma. Es cierto que puede evocar en quien la oye múltiples "contenidos", como también provocar emociones y sensaciones. Pero eso es un efecto y no un elemento constitutivo de ella misma. Desde otra perspectiva, ¿qué imita la música?, ¿ideas, sentimientos, acciones? Es una cuestión difícil de establecer. Para Aristóteles todavía imitaba acciones (seguramente en un "género" que mezclaba danza, ritmo, sonidos y poesía, todo a un tiempo), y por eso la refiere como una de las artes representativas en los dos primeros capítulos de la Poética. Pero ¿realmente la música imita acciones?, ¿cuáles?, ¿de qué tipo? El concepto ¿post-romántico? del Motif viene en nuestra ayuda, pero tampoco parece ser suficiente. Por ejemplo: no cabe duda de que la Sinfonía ${ }^{\circ}$ 6 de Gustav Mahler (1903-1904) ha sido justamente llamada "trágica”. ¿Pero de qué? ¿O acerca de qué? ¿Puede la música, como pura forma, lograr precisamente eso, transmitir una emoción pura, en sí misma, huérfana de toda acción humana? La primera vez que oí la Sexta experimenté fuertemente dicha tragicidad. Días después alguien me dijo que Mahler 
la había compuesto tras la muerte de su hija, y me resultó, por lo mismo, una experiencia epifánica. Bastante tiempo después, y tratando de ilustrar un poco mis básicos conocimientos de música "clásica", supe que no solo era incorrecto el dato que me habían dado, sino que Mahler escribió esa sinfonía en un período de especial felicidad en su vida: se casó con Alma Schindler un año antes de empezar a componerla, y durante el trabajo nació, y no murió, Maria Anna, su primera hija. Moriría muy pequeña, sí, pero en 1907, tres años después. ¿Premonición, profecía, presciencia musical? Difícil saberlo.

Como sea, a lo que quiero llegar es a lo siguiente: ¿qué es la música? Más bien, ¿por qué Lewis hace cantar a Aslan para crear Narnia? Quizá la explicación sea bastante simple: una hermosa melodía (quizá debería decir "una melodía sublime"), y que por lo mismo resulta un gozo oír, es lo más parecido a lo perfecto. $\mathrm{O}$, lo que es lo mismo pero dicho de otra manera, una espléndida metáfora -ya no abstracta sino sensible; y, en este caso, técnicamente una metáfora de carácter alegórico- de lo perfecto. Veamos: hay una misteriosa pero perfecta, unitaria y armónica relación entre las Tres Personas Trinitarias, de idéntica naturaleza: Padre, Hijo y Espíritu Santo, uno y trino. Con el Símbolo Atanasiano, se nos invita a "3. [...] que veneremos a un solo Dios / en la Trinidad Santísima / y la Trinidad en la unidad. / 4. Sin confundir las personas, / ni separar la substancia”. Pues bien: definitivamente la música, de forma análoga, es una pluralidad que conforma un todo unitario y armónico.

De hecho, y como ha señalado Vladimir Marchenkov en su trabajo The Orpheus Myth and The Powers of Music, fue precisamente la doctrina de la Santísima Trinidad, combinada "con las estéticas del contraste y el racionalismo escolástico, lo que gradualmente transformó el pensamiento musical y estimuló el auge de la polifonía medieval"14. Más aún, afirma Marchenkov que los historiadores de la música suelen remarcar que "la polifonía transformó completamente [su] creación y apreciación en Occidente"15. La clave, según él, estaría en la tesis de Ernest Ansermet, quien propuso la idea de su desarrollo desde una original y primigenia "conciencia melódica" a una "conciencia armónica"16, en cuyo centro

\footnotetext{
14 Vladimir Marchenkov, The Orpheus Myth and The Powers of Music (Pendragon Press, Hillsdale-New York, 2009) 57.

15 Vladimir MarchenKov, The Orpheus ..., 57.

16 Vladimir MarchenKov, The Orpheus ..., 57.
} 
estaría, precisamente, "la transición desde el antiguo mito a su rivalsemilla-heredero cristiano", que él llama el "mito" trinitario. Dicho en simple, la polifonía "reproduce en la música las relaciones entre las personas de la Santísima Trinidad"17. En efecto,

[...] in the terminology of the Musica enchiriadis, the vox principalis of organum represents the origin of the whole composition; it corresponds to the first person of the Trinity. This voice is then supplemented by the vox organalis that is at once identical and distinct from its own origin; it corresponds to the second person. Alongside the two simultaneous but different voices, the third critical element is the rules of harmony that define the relation between them ${ }^{18}$.

Para más detalles remito al fascinante acápite sobre la polifonía (cap. 3 del libro). En síntesis: Aslan canta al crear Narnia no solo porque la música, forma pura, es belleza captada por el sentido fundamental -el oído-, sino ante todo porque es una perfecta analogía de la perfección trinitaria del Dios cristiano. Tal vez una analogía tan apropiada como esta sería el recurso a la poesía, con esa asombrosa e inseparable unión que posee entre materia y forma; pero sabemos que, en el origen, poesía y música no se distinguen; son lo mismo. Como dijo T.S. Eliot, el inicio de la poesía fue el golpe de un tambor en la selva... Para el caso que nos ocupa, de todos modos tenemos también poesía: después de cantar, Aslan "hablará poéticamente" a los animales de Narnia.

Como adelantara, antes de concluir quiero hacer un par de comentarios particulares en torno a la fundación misma de ese mundo. Como sabemos, hacia el final del capítulo homónimo, el león escoge a algunos animales, "siempre de dos en dos"19 -clara alusión a Noé y el arca; figuras, en el Antiguo Testamento, de Jesús y de la Iglesia, respectivamente-, rozándoles el hocico con el suyo. Los no elegidos se dispersan y el resto se reúne con el león en silencio, en una suerte de gran -y primordialconcilio. Tras mirarlos fijamente y equilibrarlos en tamaño, exhala "un largo y cálido aliento, que pareció balancear a todos los animales igual que el viento balancea una hilera de árboles" ${ }^{20}$. Desde el cielo las estrellas vuelven a cantar y se produce un "veloz fogonazo parecido a una

\footnotetext{
Vladimir MarchenKov, The Orpheus ..., 57.

18 Vladimir MarchenKov, The Orpheus ..., 57-58.

19 C.S. LEWIS, El sobrino ..., 157.

20 C.S. LEWIS, El sobrino ..., 159.
} 
llamarada" 21 Entonces, "la voz más profunda e impetuosa que [los niños] habían oído jamás empezó a decir: -Narnia, Narnia, Narnia, despierta. Ama. Piensa. Habla. Sed Árboles Andantes. Sed Bestias Parlantes. Sed Aguas Divinas"22.

Lo primero que reluce es ese "largo y cálido aliento" que Aslan exhala sobre los animales, como el Ruaj bíblico: el espíritu que vivifica. Es un símil evidente del "aliento de vida" que el Señor Dios insufló en las narices de Adán, y que "lo convirtió en un ser vivo" (Gn 2, 7). Y que es figura también del soplo de Jesús sobre los apóstoles para darles el Espíritu Santo (Jn 20, 22), la nueva existencia que implica la restauración de la vida sobrenatural de las almas. Así, es Aslan quien da a los narnianos su "vida narniana"; y, por lo tanto, tras su exhalación quedan indefectiblemente unidos a él (aunque puedan, después, traicionarlo algunos...). Como Dios, Aslan vivifica a sus criaturas a través de un Ruaj, estableciendo un vínculo esencial con ellas: así como la vida de Adán viene de Dios -y la vida sobrenatural del Espíritu-, la cabal existencia de los animales en Narnia viene de Aslan. Una alianza, diríamos, para utilizar el término más apropiado (y más denso) teológicamente.

Pero, y además, las palabras con las que el león concluye su fundación son muy sugerentes. Tres veces repite el nombre del nuevo mundo (Narnia), en claro eco Trinitario. Tres veces también repite un verbo (ama, piensa, habla), para enfatizar lo mismo y constituirle a Narnia y a los narnianos su verdadera naturaleza. Y tres vocaciones repite, en fin, bajo la imprecación "Sed" ( $B e$, en inglés, que aunque es lo mismo suena más fuerte, más mandatorio); como insistiendo en que la creación es reflejo de su creador, cuya condición esencial es esa: ser.

Hay una huella en lo creado y es la de su creador. Una pisada de león, en este caso.

21 C.S. LEWIS, El sobrino ..., 159.

22 C.S. LEWIS, El sobrino ..., 159. 